\title{
SARS-CoV-2 Infection in Children; What Do We Know So Far?
}

\begin{tabular}{|c|c|c|}
\hline Author(s) & \multicolumn{2}{|l|}{ (D) Benhur Şirvan Çetin } \\
\hline Affiliation(s) & \multicolumn{2}{|c|}{$\begin{array}{l}\text { Erciyes University, Faculty of Medicine, Department of Child Health and Diseases, Pediatric Infectious } \\
\text { Diseases Unit, Kayseri, Turkey }\end{array}$} \\
\hline $\begin{array}{l}\text { Article } \\
\text { Information }\end{array}$ & $\begin{array}{l}\text { Article Type: Invited Review } \\
\text { Article Group: Pediatric Infectious Diseases }\end{array}$ & $\begin{array}{l}\text { Received: } 24.11 .2020 \\
\text { Accepted: } 17.12 .2020 \\
\text { Aviable Online: } 27.12 .2020\end{array}$ \\
\hline
\end{tabular}

Cite this article as: Çetin BŞ. SARS-CoV-2 Infection in Children; What Do We Know So Far? J Pediatr Acad 2020; 1 : 76-85.

\section{Abstract}

After Severe Acute Respiratory Syndrome Coronavirus (SARS-CoV) and the Middle East Respiratory Syndrome Coronavirus (MERS-CoV), SARS-CoV-2 is the newest member of the family of coronaviruses that are pathogenic to humans. The disease which occurs with SARS-CoV-2 is called coronavirus disease 2019 (COVID-19). COVID-19 was first described in December 2019 and has caused millions of people to get sick and hundreds of thousands of deaths over the past year. In this review, the epidemiology, diagnosis, clinical and laboratory features, radiological findings, treatment, and management of the disease are all reviewed from a pediatrician's perspective. Post-infectious complications, the impact of COVID-19 on global child health, and vaccine developments were also discussed in this review.

Keywords: SARS-CoV-2, COVID-19, MIS-C, children, infection

\section{Introduction}

Coronaviruses are single-stranded RNA viruses that cause a number of infections in animals and humans. After Severe Acute Respiratory Syndrome Coronavirus (SARS-CoV) and the Middle East Respiratory Syndrome Coronavirus (MERSCoV), SARS-CoV-2 is the newest member of the family of coronaviruses that are pathogenic to humans. The other family members of coronaviruses (229E, NL63, OC43, and HKU1) have been associated with usually mild clinical

symptoms. ${ }^{1}$ The disease which occurs with SARS-CoV-2 is called coronavirus disease 2019 (COVID-19). In early December 2019, the outbreak of COVID-19 started in Wuhan City, Hubei Province, China. On the $30^{\text {th }}$ of January, 2020, the World Health Organization (WHO) declared the outbreak as a Public Health Emergency of International Concern. On the $11^{\text {th }}$ of March, 2020, the WHO declared COVID-19 as a pandemic disease. ${ }^{2}$ SARS-CoV-2 has, up to the $15^{\text {th }}$ of November, 
2020 , caused nearly 54 million infections and 1.300 .000 deaths worldwide. ${ }^{3}$ Among 8.198.609 cases reported to the Centers for Disease Control and Prevention (CDC) in the United States (US), 9.4\% were children. ${ }^{4}$ In this review, evidences, theories, and questions about COVID-19 will be discussed from a pediatrician's perspective.

\section{Epidemiology of COVID-19 in children}

SARS-CoV- 2 is carried in the respiratory tract of infected people from nose to lungs and spread during speaking and coughing especially. Respiratory droplets, direct contact, and aerosol transmission are the primary infection routes in both children and adults. ${ }^{5}$ SARS-CoV-2 actively infects gastric, duodenal, and rectal glandular epithelial cells. The fecal-oral route has also been evaluated in the pediatric population as a potential route of transmission. Nevertheless, it has not been accepted as a major transmission route for children or adults. ${ }^{6-8}$

Infectiousness starts two days before symptom onset, peaks 0.7 days before symptom onset, and declines within seven days.9 Both symptomatic persons and asymptomatic carriers can transmit disease. Furthermore, each patient can transmit the infection to $1.5-7$ individuals. ${ }^{10}$

Worldwide, during lockdown periods, children constituted only $2 \%$ of recorded infections. ${ }^{11}$ But, after the school openings and ending of the lockdowns, the number of pediatric cases increased dramatically. In the US, pediatric cases were $1.7 \%$ of all cases in the first months of the pandemic, but this ratio increased to $11.5 \%$ nowadays. ${ }^{4,12,13}$ The recent report from the US, the overall rate of COVID-19 is 1,381 cases per 100,000 children in the population. Between two weeks $(10 / 29-11 / 12)$, the rate of the increase in childhood cases was reported as $22 \% .^{13}$ Early studies during the lockdowns showed that most children appeared to acquire infection from positive adults, especially within the family. On the other hand, when children have had contact with people infected with COVID-19, they are probably less likely to contract the infection than adults. Having an infected parent was associated with a marked increase in risk for secondary infection in a child.

Recent meta-analyses suggest that children's overall susceptibility is approximately half of adults, with the most significant effect on younger children. ${ }^{14,15}$ Numerous largescale studies have indicated that children, particularly children $<10$ years, have much lower infection rates than adults. 16,17 Schools or child care facilities are other potential areas for outbreaks. In countries with strict mitigation regulations like Ireland, Australia, Singapore, and Germany, there were reported no to the little facilitybased transmission of SARS-CoV-2 by children despite the presence of infected children. ${ }^{18-21}$ However, in areas with widespread community transmission or less strict mitigation procedures, large outbreaks have occurred. ${ }^{22-24}$
These outbreaks reveal that infected adults are typically responsible for introducing viruses into these settings.

Infected children generally had mild symptoms and were less likely than adults to report lower respiratory tract symptoms or loss of taste or smell. Asymptomatic, mild, and moderate cases account for $98 \%$ of childhood cases. ${ }^{25}$ Mortality rate is also much lower than that in adults. In the US, from the beginning of the pandemic, mortality in children ( $<18$ years of age) accounts for $<0.41 \%$ of all deaths. ${ }^{4}$ The differences in clinical outcomes between children and adults with COVID-19 suggest that age-dependent host features are important contributors to the disease's pathophysiology. There are some possible answers to this question with the studies done so far. Children are more likely to have other viruses in their upper respiratory tract, and associations and competition of these viruses with SARSCoV-2 can hinder their ability to cause infection. ${ }^{11}$ SARSCoV-2 enters into host cells by Angiotensin-Converting Enzyme 2 receptors (ACE2-r). These receptors are expressed in various tissues, especially alveolar epithelial cells, nasal and intestinal epithelium. Different from adults, children have significantly lower levels of ACE2-r in their nasal epithelium. This difference may make them less susceptible to infection. ${ }^{26}$ Additionally, previous exposure to other seasonal human coronaviruses may also provide a level of protection through cross-reactive T-cells against SARS-CoV-2. ${ }^{27}$ Differences in immune responses of children and adults to SARS-CoV-2 are another main reason why the clinical course of COVID-19 is different in children and adults. New findings suggest that children with COVID-19 do better than adults because their stronger innate immunity protects them against SARSCoV-2 related complications like acute respiratory distress syndrome (ARDS), while adult patients respond to infection with an over-vigorous adaptive immune response that may promote the inflammation associated with ARDS. ${ }^{28}$ The low mortality rates and the mild course of the disease are also frequently debated whether childhood vaccines will have a role. There may be a possibility that heterologous immunity developed against traditional childhood vaccines may positively affect COVID-19 infections in children. In this context, especially Bacillus Calmette-Guerin (BCG) and measles, mumps, and rubella (MMR) vaccines have been the subject of some studies, but there has not been sufficient evidence that childhood vaccines are protective against COVID-19. There are still unexplained points regarding the different epidemiological and clinical features of COVID-19 between children and adults. Therefore, it will remain important to explain the mechanisms responsible for differences in symptomatology, sensitivity, and infectivity between adults and children. 


\section{Virologic Diagnostic Tests}

For the diagnosis of acute infection, detecting SARS-CoV-2 RNA from the nose and oropharynx is crucial. Real-time RT-PCR-based testing from the nasal and oropharyngeal swab is recommended. RT-PCR tests can also be used for other respiratory samples like endotracheal aspirate or bronchoalveolar lavage. Many factors affect the accuracy of testing include the quality of the sample, the material used for sampling, stage of the disease, and viral load in the patient. In clinical settings, the false-negative test rates have been reported between $10 \%$ to $40 \%{ }^{29}$ When the clinical suspicion is high, the tests should be repeated. Overall, RT-PCR for SARS-CoV-2 has a high specificity of $95 \%$ but a lower sensitivity of approximately $70 \%{ }^{30}$ Most studies on contagiousness are depended on viral RNA detection from respiratory specimens. Viral replication stops 5 to 7 days after the onset of symptoms, but patients can remain RNA-positive for days and weeks. It is essential to remind that prolonged viral RNA detection following illness resolution does not necessarily indicate infectiousness. ${ }^{7,10,25,30-32}$ Saliva specimens may be an alternative diagnostic sample for RT-PCR based tests. These tests may be more comfortable and safer during the sample collection. Studies from the US and Canada suggest that saliva testing is as sensitive as nasopharyngeal swab testing in high-risk populations. ${ }^{33,34}$

Serological testing for SARS-CoV-2 (IgM and $\operatorname{lgG}$ ) can detect recent or previous infection. The tests' sensitivity and specificity vary depending on the type, timing, and manufacturer of the test. While the specificity rates vary between $96.6 \%$ to $99.7 \%$, sensitivity rates are between $66 \%$ to $97.8 \%$. The tests that have no authorization from the United States Food and Drug Administration (FDA) or the European Medicines Agency (EMA) should not be used.

Antigen tests are another alternative for diagnosing acute infection rapidly. Most commercially available antigen tests detect the nucleocapsid $(\mathrm{N})$ or spike $(\mathrm{S})$ proteins of the virus by using enzyme-linked immunosorbent assay. Despite the lower price and easy usage of these tests, their sensitivity is less than that of nucleic acid amplification tests typically. ${ }^{35}$

\section{Clinical and Laboratory Features}

Children of all age groups can be infected with COVID-19. From the studies, there is no age or sex preponderance. ${ }^{25}$ The incubation period is usually between 5-6 days but may reach up to 14 days. In COVID-19, the spectrum of the clinical features in children varies from asymptomatic to critical illness. The commonest presenting features in children are fever, coryzal symptoms, cough, lethargy, and shortness of breath. Respiratory symptoms are not the only features of COVID-19 in children. Abdominal pain, vomiting, and diarrhea are common gastrointestinal symptoms present with or without respiratory symptoms. Unlike adults, dermatologic lesions are more common in children and can be seen in up to $20 \%$ of patients. The common manifestations are maculopapular rash, urticarial eruptions, and transient livedo reticularis and pernio (chilblain)-like acral lesion. ${ }^{36}$ Dermatological lesions can be easily misinterpreted and confused with other viral infections or non-infectious diseases. Around 10\% of hospitalized children with COVID-19 have additional infectious diseases such as urinary tract infection, appendicitis, and sepsis. ${ }^{11}$

Patients with COVID-19 may be grouped in 5 clinical pictures: Asymptomatic infection, mild, moderate, severe, and critically severe infection. Severely ill cases are defined as those with central cyanosis and pneumonia, and critically ill cases develop acute respiratory distress syndrome that necessitates mechanical ventilation. Between $15 \%$ and $20 \%$ of virologically positive cases remain asymptomatic during the disease course in children. Meanwhile, most of the symptomatic cases often have mild to moderate symptoms in severity and can be cared for in the home. ${ }^{37,38}$ As noted, the disease is more likely to be mild in children than adults. In a review in which 2228 children were evaluated, severe disease rate also reported that only $6 \%$ of infected patients. ${ }^{39}$ Mortality rates are also very low in children compared to adults. The overall death rate in adults appears to be $2 \%$ to $3 \% .{ }^{40}$ In contrast, only two deaths $(0.09 \%)$ were reported in the recent review of 2228 children. ${ }^{39}$ Although children represent a growing percentage of total cases, hospitalization, and death due to COVID-19 are still uncommon in all countries. In the US, children were $1.2-3.3 \%$ of total reported hospitalizations, and between $0.5 \%-6.1 \%$ of all child, COVID-19 cases resulted in hospitalization. The rates are varying between states. Mortality rates also varied between the states, and 16 states reported zero child deaths in the US. As the last reports from the US, $0.00 \%-0.15 \%$ of all child COVID-19 cases resulted in death, and children made up $0.07 \%$ of total deaths. ${ }^{13,41}$

The laboratory characteristics of acute COVID-19 are variable in children, and a large proportion of them have normal values. ${ }^{11}$ In adults, lymphopenia is the most common abnormality in complete blood count. ${ }^{42}$ Limited studies in children describe relatively lower rates of lymphopenia. Additional to lymphopenia, elevated inflammatory markers, including $C$ Reactive Protein (CRP) and procalcitonin, have been documented in children but are by no means universal. ${ }^{43,44}$ Acute phase reactants like CRP, procalcitonin, erythrocyte sedimentation rate, ferritin, D-dimer, fibrinogen, and interleukin- 6 are the most studied laboratory markers in COVID-19. An elevated marker of inflammation should point toward more severe disease and alert the clinician about the possibility of the multisystem inflammatory syndrome in children (MIS-C) associated with SARS-CoV-2 which is discussed in another section. ${ }^{7}$

\section{Radiological Findings}

Chest x-ray findings in COVID-19 are usually non-specific, and bilateral infiltrates like any other viral infections can be seen. Pleural effusion is an uncommon finding. ${ }^{45}$ When chest radiography has been performed in children with COVID-19, no specific features are found to be diagnostic. Therefore, chest $\mathrm{X}$-ray indications remain as they were before the pandemic. It should be remembered that X-ray findings may be normal in the early phases of the disease. ${ }^{46}$ Computed tomography (CT) can show early changes in the lungs independent from the clinical symptoms. The radiological findings of subpleural lesions, bilateral peripherally distributed ground-glass opacities 
(GGOS), and patchy alveolar infiltrations with lower lobe predominance are common findings in children in COVID-19 (Figure 1). ${ }^{46,47}$ In addition to the GGOs and patchy alveolar infiltrations, the reversed halo sign can also be noted in children. ${ }^{48}$ The critical point about imaging is performing a CT did not alter the management of the majority of these children. ${ }^{47}$ It should be reminded that radiologic findings may not always be consistent with the clinical picture and may continue to persist for weeks even after the resolution of clinical symptoms. ${ }^{7}$ Children with COVID-19 who have radiological evidence of pneumonia are significantly more likely to require intensive care unit (ICU) admission. .11,38 $^{2}$

\section{Special patient groups}

In adults, certain comorbidities like hypertension, chronic respiratory and cardiovascular diseases, obesity, diabetes, immune-compromised status, chronic kidney disease, smoking, and obesity have all been identified as an important risk factor for poor prognosis. ${ }^{7}$ In the first international multicentric pediatric COVID-19 studies in Europe, significant risk factors found for requiring ICU admission were being younger than one month, male sex, pre-existing medical conditions, and presence of lower respiratory tract infection signs or symptoms at presentation.38 However, in children and adolescents, there is a need for more data to understand how preexisting conditions can influence the course of COVID-19.

Neonates have been reported to have COVID-19 but rare. Evidences for transmission of the SARS-CoV-2 virus through the placenta or viral transmission through the birth canal during the labor is not clear. The majority of infected neonates are believed to have contracted COVID-19 after birth. Although compared to all children, age under one month is a risk factor for ICU admission in COVID-19, neonates have not usually required ICU admission. ${ }^{38}$ In a systemic review, we see that most neonates with SARS-CoV-2 infection are asymptomatic or presented mild symptoms, generally have a good prognosis after a median of 10 days of hospitalization. ${ }^{49}$ With current findings, neonatal guidelines do not recommend against breastfeeding for mothers with COVID-19. No replicable virus has been identified in breast milk yet.50 During the breastfeeding period, contact precautions, use of maternal masks, hand hygiene before and after touching baby, social distancing from other individuals, limiting all contacts must be followed meticulously. ${ }^{51}$
Although recent studies have found that adults with cancer and COVID-19 have a higher death rate, this does not appear to hold for pediatric cancer patients. Boulad et al. ${ }^{52}$ find that the overall morbidity of COVID-19 in pediatric patients with cancer is low, with only $5 \%$ requiring hospitalization for symptoms of COVID-19. Additionally, they showed that the rate of SARS-CoV-2 infection among asymptomatic pediatric patients was very low compared with their asymptomatic caregivers $(2.5 \%$ and $14.7 \%$, respectively).

As in adults, children with the following conditions might be at increased risk for severe illness: obesity, medical complexity, severe genetic disorders, severe neurologic disorders, inherited metabolic disorders, sickle cell disease, congenital (since birth) heart disease, diabetes, chronic kidney disease, asthma and other chronic lung diseases, and immune-weakening medications. ${ }^{2,32,38,53,54}$ Several other aspects could be implicated in the severity of COVID-19 in children, such as coinfection with RSV, the immune system's responsiveness, vaccination history, and levels of vitamin D, and genetic polymorphisms. However, the present paucity of data limits the ability to draw such conclusions. ${ }^{32}$

\section{Clinical management and treatment options}

Most children with COVID-19 require only supportive therapy (e.g., acetaminophen and hydration for fever and lessen fluid uptake), with less than $25 \%$ of hospitalized children requiring oxygen and far fewer requiring ventilatory support. ${ }^{11}$ Difficulty in breathing, cyanosis, undefined chest pain, altering mental status, poor feeding, and decreased urine out are the clinicians' main alarming points. Patients with underlying medical conditions and those who present with severe and life-threatening clinical features require hospital admission. Patients should be monitored for clinical deterioration. Supportive care is the primary treatment for these patients. Fever control, respiratory support (oxygen supplementation, non-invasive, and invasive ventilation), adequate nutrition, and fluid replacement are the main supportive care approaches. In more severe cases, renal replacement therapy and extracorporeal membrane oxygenation may be needed. In children receiving immunosuppression therapy, the risk and benefit of reducing immune suppression must be evaulated..$^{55}$

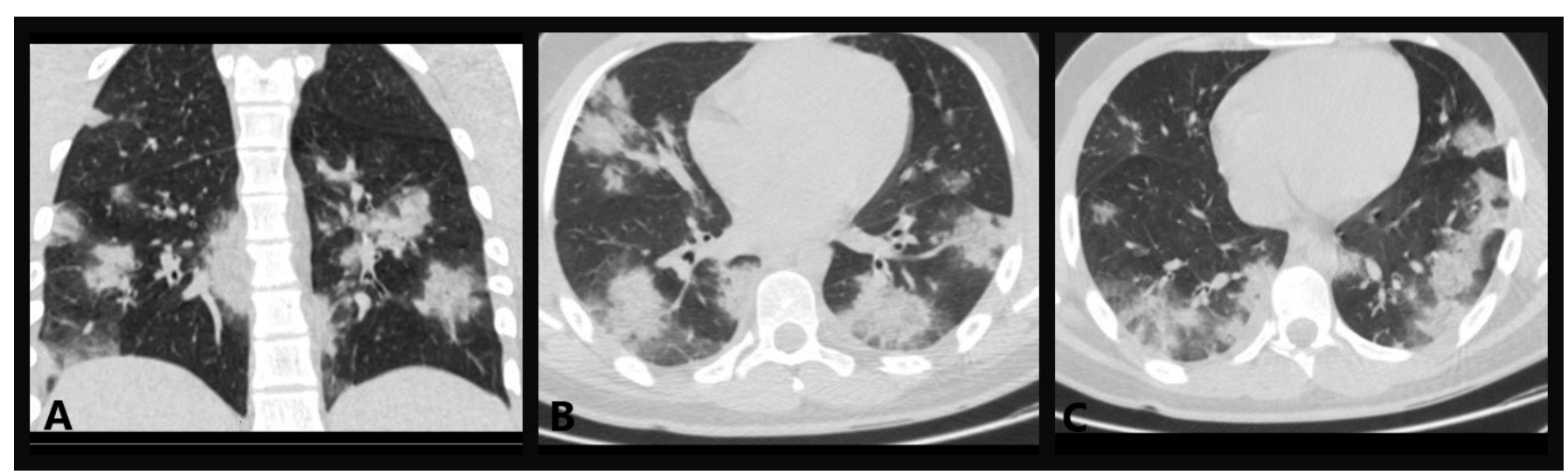

Figure 1. Computed chest tomography findings of a child with COVID-19; subpleural lesions, bilateral peripherally distributed ground-glass opacities, and patchy alveolar infiltrations, especially in lower lobes (A: Coronal reconstruction plane, B and C: horizontal planes). 
Corticosteroids: Current literature shows that the most effective agent for reducing mortality in critically unwell adults with COVID-19 is dexamethasone ${ }^{56}$ The safety and effectiveness of corticosteroids have not been sufficiently evaluated in pediatric COVID-19 patients. Dexamethasone or another corticosteroid is not recommended for mild pediatric patients who require low levels of oxygen support. As in the adult studies, corticosteroids may be beneficial in critical pediatric COVID-19 patients with respiratory disease who require mechanical ventilation. ${ }^{57}$

Remdesivir: Remdesivir is a nucleotide analog that inhibits RNA-dependent RNA polymerase. It was first developed for Ebola therapy in 2017 by Gilead and has been found to have in vitro activity against coronaviruses. At the beginning of the pandemic, studies showed in vitro activity of remdesivir against SARS-CoV- 2. In April 2020, the American Pediatric Infectious Diseases Society suggested remdesivir for COVID-19 treatment in children if an antiviral is used. ${ }^{58}$ Meanwhile, the drug has received emergency authorization by the FDA for emergency use in both children and adults with severe COVID-19 disease in May 2020.59 The current dose of remdesivir in pediatrics is $5 \mathrm{mg} / \mathrm{kg}$ (maximum dose 200 $\mathrm{mg}$ ) IV loading dose on day 1 , followed by $2.5 \mathrm{mg} / \mathrm{kg}$ (maximum dose $100 \mathrm{mg}$ ) IV every 24 hours for 5 to 10 days. ${ }^{59}$ Based on the results of recent multicenter studies, on $20^{\text {th }}$ of November, WHO has issued a conditional recommendation against the use of remdesivir in hospitalized patients, regardless of disease severity, as there is currently no evidence that remdesivir improves survival and other outcomes in these patients. ${ }^{60}$

Favipiravir: Favipiravir is a guanine analog that inhibits RNA polymerase. It is approved for the treatment of influenza virus infection in Japan previously. None of the European, US, and WHO guidelines recommend favipiravir for the treatment of COVID-19 for now. ${ }^{57,60,61}$ The potential of this drug remains unclear and requires additional clinical studies before any recommendations can be offered.

Convalescent Plasma: In phase II, randomized controlled trial in India (PLACID trial), investigators found no net benefit associated with convalescent plasma in patients admitted to hospital with moderate COVID-19. Using convalescent plasma was not associated with a reduction in progression to severe covid-19 or all-cause mortality. Small beneficial effects were found for the resolution of shortness of breath and fatigue. ${ }^{62}$ We have not sufficient data to recommend either for or against the use of convalescent plasma to treat COVID-19 in adults yet. Additionally, the safety and effectiveness of convalescent plasma have not been evaluated in pediatric patients. Clinical trials of convalescent plasma in COVID-19 treatment in children are ongoing. ${ }^{57}$

Venous thromboembolism prophylaxis: COVID-19 seems to be associated in adults with an increased risk of disseminated intravascular coagulation and venous thromboembolism, but children have a much lower incidence of thrombotic complications than adults. Preventive anticoagulant therapy can be considered for neonates and adolescents in cases where severe inflammatory conditions and hyperactivation of the clotting process can occur. In these groups, the suggested treatment is with subcutaneous enoxaparin $100-200 \mathrm{U} / \mathrm{kg} / \mathrm{day}$, which can be increased to $150-300$ $\mathrm{U} / \mathrm{kg} /$ day in neonates. ${ }^{61}$

Other drugs and supplements: Currently, because of the lack of a strong rationale and the absence of evidence of certain effects in the treatment of COVID-19 patients, guidelines recommendations are against to use hydroxychloroquine, chloroquine, azithromycin, lopinavir/ritonavir, or ivermectin for the treatment in adults and children both in inpatient and outpatient settings. ${ }^{57,60}$ Antibacterial and antifungal agents should be used only when an infection is suspected/confirmed. If it is needed, anti-infective agents should be used according to local guidelines and clinical/laboratory assessments. ${ }^{7}$ In the management of COVID-19, the function of vitamin and mineral supplements such as vitamin $C$, vitamin $D$, vitamin $A$, and zinc remains uncertain. There is not yet a well-designed controlled study to evaluate their effects. Until more data become available, dietary supplements should be avoided if there is no documented deficiency. ${ }^{62}$

\section{Vaccine studies}

Many potential vaccines for COVID-19 are being studied, and several large clinical trials are ongoing. At the time of writing this article, 56 vaccines have been testing in clinical trials, and at least 200 vaccine candidates are under investigation in the pre-clinical stage. Currently, 11 vaccines are in the final stages of phase studies. ${ }^{63}$ In China and Russia, some vaccines had received limited approval for use before the phase 3 trial results. The WHO is actively involved in the progress of vaccine discovery and development. The first preliminary data about effectiveness from phase 3 trials came in November 2020. Firstly, Pfizer and BioNTech announced that their coronavirus vaccine is $95 \%$ effective on the 9th of November. A week later, Moderna, another company that works with the National Institutes of Health in the US, announced that their vaccine is $94.5 \%$ effective. On the $20^{\text {th }}$ of November, a request for an emergency use authorization to FDA was submitted by Pfizer. ${ }^{64}$ The Moderna's and Pfizer's vaccines are based on messenger RNA (mRNA) technology.

Meanwhile, many other phase 3 clinical trials with different vaccines are ongoing. The two vaccines from the Johnson \& Johnson/Beth Israel Deaconess Medical Center collaboration and the AstraZeneca/University of Oxford collaboration are both viral vector vaccines. Phase 3 studies of both are ongoing. At the time of this review, AstraZeneca was the last company to share its phase 3 trial results. On the $23^{\text {rd }}$ of November, AstraZeneca and Oxford announced that their vaccine has an average $70 \%$ efficacy. ${ }^{64}$ Johnson \& Johnson phase 3 trial results have not been announced yet. ${ }^{7,65}$ From China, CanSino Biologics's vaccine is a viral vector vaccine while Sinovac Biotech's and Sinopharm's vaccines are inactivated vaccines. All these three vaccines are in the phase 3 stage and received approval for limited use in China. Gamaleya Research Institute and Vector Institute developed two different vaccines that received approval before a phase 3 trial from Russia. The results of phase 3 trials of the Russian vaccines are pending. ${ }^{63,64}$ In early 
2021, at least one vaccine is expected to be available for use in Europe and the US. Because of the benign nature of the disease and limited resources, the use of a COVID-19 vaccine in healthy children will remain controversial. With the results of future phase studies in children, the need for vaccination can be determined by clinical evaluation on a case-by-case basis.

\section{Multisystem inflammatory syndrome in children (MIS-C)}

MIS-C is an emerging phenotype of illness that is consistent with inflammation and organ dysfunction in the absence of another apparent cause. This phenomenon is a rare complication of COVID-19 in children; however, the presentation can overlap with acute COVID-19 illness or be a delayed response up to six weeks. ${ }^{11}$ In the study from the New York State, the estimated incidence of MIS-C was 2 per 100,000, but the incidence of MIS-C is not known exactly yet. ${ }^{66}$ While this syndrome is named as MIS-C by the National Institutes of Health in the US, and it has also been named in different institutions as pediatric inflammatory, multisystem syndrome temporally associated with SARS-CoV-2 (PIMS-TS). ${ }^{7}$ Children usually present with persistent fever, but the presentation of MIS-C is varied. Skin and mucous membrane changes like a polymorphic rash, non-purulent conjunctivitis, and cracked lips (Figure 2), hand and foot swelling, and gastrointestinal disturbance are the other common findings. ${ }^{67}$ Abdominal pain is present in over $50 \%$ of children. Children can be presented acutely unwell with vasodilatory shock features or features consistent with complete or incomplete Kawasaki Disease (KD). In contrast, others may have more non-specific features. ${ }^{68}$ MIS-C is thought to be a post-infectious phenomenon triggered by an abnormal immune response after the acute infection. Laboratory findings in these children are characterized by lymphopenia, anemia, thrombocytopenia, and elevated inflammatory markers. The inflammatory markers studied mainly in MIS-C are $\mathrm{CRP}$, procalcitonin, B-type natriuretic peptide (BNP), erythrocyte sedimentation rate, ferritin, fibrinogen, D-dimer, interleukin-6, and interleukin-8. Increased levels of CRP, BNP, troponin were reported in most of the studies. ${ }^{69}$ Echocardiography can demonstrate decreased left ventricular ejection fraction, myocarditis, pericardial effusion, and a coronary artery abnormality, including dilation or aneurysm. The rates of cardiac involvement differ from $25 \%$ to $70 \%$ in studies. ${ }^{66,68,69}$ The diagnosis relies on the CDC or WHO case definition criteria (Table 1). ${ }^{68,70}$

Management of MIS-C should involve a multidisciplinary care team with pediatric infectious diseases, intensive care, pediatric cardiology, and rheumatology specialists. American College of Rheumatology has published clinical guidance for diagnostic and therapeutic management for MIS-C recently. ${ }^{71}$ Treatment involves supportive care, management of shock and left ventricular dysfunction, and other critical care support. ${ }^{7,68}$ Intravenous immunoglobulin (IVIG) and glucocorticoids are the main backbones of the therapy in MIS-C. If the inflammation persists despite IVIG and glucocorticoid therapy, other drugs that could be a choice include anakinra, tocilizumab, and infliximab, used to manage other cytokine release syndromes. ${ }^{7,68-72}$ Anakinra targets IL-1ß, and it has been widely used in many other inflammatory conditions like rheumatoid arthritis, juvenile idiopathic arthritis. Tocilizumab, another immunomodulator, targets IL-6, and it has been mainly studied in adults to date. Anakinra has some advantages from tocilizumab. Anakinra has a short half-life, whereas tocilizumab has a one-month half-life, so anakinra can be discontinued rapidly if it is not effective or has side effects. We have experience with anakinra's effects on children. However, pediatricians do not have much experience with tocilizumab in the setting of severe infections. Antibiotics should be given for suspected or confirmed concurrent bacterial infection. Due to the post-infectious nature of the disease and the negative PCR tests for SARS-CoV-2 in most cases, it is thought that remdesivir would not be effective in treatment. ${ }^{67}$ In children who meet KD's criteria, IVIG and aspirin should be started as the standard KD therapy. ${ }^{68}$ Because of the risk of coronary artery aneurysms, echocardiographic follow-up is essential in all MIS-C patients. ${ }^{69}$ Duration of hospitalization ranged from 4 to 13 days, and favorable outcomes are reported with a mortality rate between $1.4-1.7 \% .^{69}$



Figure 2. Examples of mucocutaneous manifestations of MIS-C. A child with an erythematous polymorphic rash on the back (A) and her face with cracked lips (B). Characteristic non-purulent conjunctivitis in another child (C). 


\section{CDC case definition}

\section{All 4 criteria must be met:}

1. Age $<21$ years

2. Clinical presentation consistent with MIS-C, including all of the following:

Fever:

- Documented fever $>38.0^{\circ} \mathrm{C}\left(100.4^{\circ} \mathrm{F}\right)$ for $\geq 24$ hours

or

- Report of subjective fever lasting $\geq 24$ hours

- Laboratory evidence of inflammation

- Including, but not limited to, any of the following:

- Elevated CRP

- Elevated ESR

- Elevated fibrinogen

- Elevated procalcitonin

- Elevated D-dimer

- Elevated ferritin

- Elevated LDH

- Elevated IL-6 level

- Neutrophilia

- Lymphocytopenia

- Hypoalbuminemia

Multisystem involvement

- 2 or more organ systems involved:

- Cardiovascular (eg, shock, elevated troponin, elevated BNP, abnormal echocardiogram, arrhythmia)

- Respiratory (eg, pneumonia, ARDS, pulmonary embolism)

- Renal (eg, AKI, renal failure)

- Neurologic (eg, seizure, stroke, aseptic meningitis)

- Hematologic (eg, coagulopathy)

- Gastrointestinal (eg, abdominal pain, vomiting, diarrhea, elevated liver enzymes, ileus, gastrointestinal bleeding)

- Dermatologic (eg, erythroderma, mucositis, other rash)

-Severe illness requiring hospitalization

3. No alternative plausible diagnoses

4. Recent or current SARS-CoV-2 infection or exposure

Any of the following:

- Positive SARS-CoV-2 RT-PCR

- Positive serology

- Positive antigen test

- COVID-19 exposure within the 4 weeks prior to the onset of symptoms

\section{WHO case definition}

\section{All 6 criteria must be met:}

1. Age 0 to 19 years

2. Fever for $\geq 3$ days

3. Clinical signs of multisystem involvement

(at least 2 of the following):

- Rash, bilateral nonpurulent conjunctivitis, or mucocutaneous inflammation signs (oral, hands, or feet)

- Hypotension or shock

- Cardiac dysfunction, pericarditis, valvulitis, or coronary abnormalities (including echocardiographic findings or elevated troponin/BNP)

- Evidence of coagulopathy (prolonged PT or PTT; elevated D-dimer)

- Acute gastrointestinal symptoms (diarrhea, vomiting, or abdominal pain)

4. Elevated markers of inflammation

(eg, ESR, CRP, or procalcitonin)

5. No other obvious microbial cause of inflammation, including bacterial sepsis and staphylococcal/streptococcal toxic shock syndromes

6. Evidence of SARS-CoV-2 infection

-Any of the following:

- Positive SARS-CoV-2 RT-PCR

- Positive serology

- Positive antigen test

- Contact with an individual with COVID-19

CDC: Centers for Disease Control and Prevention; WHO: World Health Organization; MIS-C: multisystem inflammatory syndrome in children; CRP: C-reactive protein; ESR: erythrocyte sedimentation rate; LDH: lactate dehydrogenase; IL-6: interleukin-6; BNP: brain natriuretic peptide; ARDS: acute respiratory distress syndrome; AKI: acute kidney injury; SARS-CoV-2: severe acute respiratory syndrome coronavirus 2; RT-PCR: real-time polymerase chain reaction; COVID-19: coronavirus disease 2019; PT: prothrombin time; PTT: partial prothrombin time.

\section{Impact of COVID-19 on child health}

In many places, especially in low-and middle-income countries (LMICs), the impact of COVID-19 on children will be more significant than the impact of the virus itself. Many major causes of poor health and mortality in children are expected to increase due to the pandemic and the response. ${ }^{73}$ The economic impact of enforced lockdown and social distancing can increase violence and addictive behaviors (e.g., alcohol, junk food, and other substances). Since the beginning of the COVID-19 pandemic, violence against women and girls has increased in different countries. ${ }^{11,74}$ The spread and severity of COVID-19 are also expected to be further exacerbated in LMICs because of the inadequate sanitation facilities, crowded living conditions, and difficult access to healthcare. Healthcare services are now severely compromised due to closures, lack of personal protective equipment, and fear of attending health facilities.
During the pandemic, well-child care visits should not be deferred because of COVID-19 disease; growth and development of infants should be followed up regularly according to the local guidelines. Telemedicine can be an option during the lockdowns and in high-risk situations. All childhood vaccines should be given in accordance with the recommendations of the WHO or the Ministry of Health. Due to COVID-19 measures, approximately 80 million children under the age of 1 in at least 68 countries may miss receiving life-saving vaccines. ${ }^{75}$ Vaccination activities have been delayed or suspended in at least 27 countries to prevent the spread of COVID-19, despite several having ongoing measles epidemics. ${ }^{73}$ Childhood malaria deaths are also predicted to double this year due to the downscaling of prevention and treatment. ${ }^{76}$ The World Food Programme predicts a doubling of malnutrition, disproportionately affecting children. ${ }^{77}$ In a modeling study, Roberton $T$ et al. ${ }^{78}$ showed that if routine health care is disrupted and 
access to food is decreased over six months, it would result in nearly 1 million excess child deaths in 118 lowincome and middle-income countries.

Children's teaching in schools were in crisis in many countries, and the pandemic has sharpened inequities, especially in poorer countries. Many schools lack the resources to invest in digital learning, and many children from poorer households do not have internet access. Unicef reported that at least 463 million-or 31 percentof schoolchildren worldwide could not be reached by digital and broadcast remote learning programs. ${ }^{75}$ We know from the history that school closures have secondary effects on increasing in child marriage and child labor. These often prevent children from continuing their education and effects negatively on their health status. We can see the secondary effects of COVID-19 for years, and the wounds of the pandemic in children may take much longer to heal.

\section{Conclusion}

In summary, children at any age may be infected with SARS-CoV-2, with reduced frequency and severity compared with adults. Infected children are mainly asymptomatic or develop only mild symptoms. Most children with COVID-19 can be managed symptomatically without hospitalization. The treatment of severe disease is essentially supportive. We still need evidence-based diagnostic and treatment guidelines for children. On the other hand, the recently identified MIS-C may pose an additional threat. The treatment of this rare phenomenon involves the use of immunomodulators, as well as supportive care. Data on the outcome of antiviral treatments, the safety and immunogenicity of vaccinations, and better specification of high-risk patients in the pediatric population are still needed. COVID-19 is a new disease, and the pandemic continues to evolve. The mid- and long-term effects of this pandemic on child health need to be evaluated by medical and social aspects. Further studies will help to understand the complete picture of the COVID-19 in the pediatric population.

Conflict of Interest Statement: The authors have no conflicts of interest to declare.

Financial Disclosure: The authors declared that this study has received no financial support.

Informed Consent: Written consent form obtained from the patient and parents for the photos.

Peer-review: Externally peer-reviewed.

\section{References}

1. Cheng ZJ, Qu H-Q, Tian L, Duan Z, Hakonarson H. COVID-19: Look to the Future, Learn from the Past. Viruses. 2020;12:1226. [CrossRef]

2. World Health Organization. Coronavirus disease (COVID-19) Weekly Epidemiological Update and Weekly Operational Update. Accessed the 5th of November, 2020. [CrossRef]

3. Johns Hopkins University \& Medicine. Coronavirus Resource Center. Accessed the 5th of November, 2020. [CrossRef]

4. US Centers for Disease Control and Prevention. CDC COVID Data Tracker. Accessed the 17th of November, 2020. [CrossRef]
5. van Doremalen N, Bushmaker T, Morris DH, et al. Aerosol and Surface Stability of SARS-CoV-2 as Compared with SARS-CoV-1. N Engl J Med. 2020;382:1564-1567. [CrossRef]

6. Koh WC, Naing L, Chaw L, et al. What do we know about SARSCoV-2 transmission? A systematic review and meta-analysis of the secondary attack rate and associated risk factors. Leekha S, ed. PLoS One. 2020;15:e0240205. [CrossRef]

7. Rathore V, Galhotra A, Pal R, Sahu KK. COVID-19 pandemic and children: A review. J Pediatr Pharmacol Ther. 2020;25:574-585. [CrossRef]

8. Manti S, Licari A, Montagna L, et al. SARS-CoV-2 infection in pediatric population. Acta Biomed. 2020;91:e2020003. [CrossRef]

9. He X, Lau EHY, Wu P, et al. Temporal dynamics in viral shedding and transmissibility of COVID-19. Nat Med. 2020;26:672-675. [CrossRef]

10. Liu Y, Gayle AA, Wilder-Smith A, Rocklöv J. The reproductive number of COVID-19 is higher compared to SARS coronavirus. J Travel Med. 2020;27. [CrossRef]

11. Bogiatzopoulou A, Mayberry H, Hawcutt DB, et al. COVID-19 in children: what did we learn from the first wave? Paediatr Child Health (Oxford). 2020. [CrossRef]

12. Bialek S, Gierke R, Hughes M, McNamara LA, Pilishvili T, Skoff T. Coronavirus Disease 2019 in Children - United States, the 12th of February-the 2nd of April, 2020. MMWR Morb Mortal Wkly Rep. 2020;69:422-426. [CrossRef]

13. American Academy of Pediatrics. Children and COVID-19: State-Level Data Report. Accessed the 16th of November, 2020. [CrossRef]

14. Goldstein E, Lipsitch M, Cevik M. On the effect of age on the transmission of SARS-CoV-2 in households, schools and the community. J Infect Dis. Published online the 29th of October, 2020. [CrossRef]

15. Viner RM, Mytton OT, Bonell C, et al. Susceptibility to SARSCoV-2 Infection Among Children and Adolescents Compared With Adults. JAMA Pediatr. Published online the 25th of September, 2020. [CrossRef]

16. Pollán M, Pérez-Gómez B, Pastor-Barriuso R, et al. Prevalence of SARS-CoV-2 in Spain (ENE-COVID): a nationwide, populationbased seroepidemiological study. Lancet. 2020;396:535-544. [CrossRef]

17. Gudbjartsson DF, Helgason A, Jonsson H, et al. Spread of SARSCoV-2 in the Icelandic Population. N Engl J Med. 2020;382:23022315. [CrossRef]

18. Lee B, V. Raszka W. COVID-19 in Children: Looking Forward, Not Back. Pediatrics. Published online October 8, 2020:e2020029736. [CrossRef]

19. Yung CF, Kam K, Nadua KD, et al. Novel Coronavirus 2019 Transmission Risk in Educational Settings. Clin Infect Dis. Published online the 25th of June, 2020. [CrossRef]

20. Macartney K, Quinn HE, Pillsbury AJ, et al. Transmission of SARSCoV-2 in Australian educational settings: a prospective cohort study. Lancet Child Adolesc Heal. 2020;4:807-816. [CrossRef]

21. Heavey L, Casey G, Kelly C, Kelly D, McDarby G. No evidence of secondary transmission of COVID-19 from children attending school in Ireland, 2020. Eurosurveillance. 2020;25. [CrossRef]

22. Fontanet A, Tondeur L, Madec $Y$, et al. Cluster of COVID-19 in northern France: A retrospective closed cohort study. medRxiv. Published online the 1st of January, 2020:2020.04.18.20071134. [CrossRef]

23. Lopez AS, Hill M, Antezano J, et al. Transmission Dynamics of COVID-19 Outbreaks Associated with Child Care Facilities - Salt Lake City, Utah, April-July 2020. MMWR Morb Mortal Wkly Rep. 2020;69:1319-23. [CrossRef]

24. Stein-Zamir C, Abramson N, Shoob H, et al. A large COVID-19 outbreak in a high school 10 days after schools' reopening, Israel, May 2020. Eurosurveillance. 2020;25. [CrossRef]

25. Dong $\mathrm{Y}, \mathrm{Mo} \mathrm{X}, \mathrm{Hu} \mathrm{Y}$, et al. Epidemiology of COVID-19 Among Children in China. Pediatrics. 2020;145:e20200702. [CrossRef]

26. Bunyavanich S, Do A, Vicencio A. Nasal Gene Expression of Angiotensin-Converting Enzyme 2 in Children and Adults. JAMA. 2020;323:2427-2429. [CrossRef]

27. Mateus J, Grifoni A, Tarke A, et al. Selective and cross-reactive SARS-CoV-2 T cell epitopes in unexposed humans. Science (80). 2020;370:89-94. [CrossRef] 
28. Pierce CA, Preston-Hurlburt P, Dai Y, et al. Immune responses to SARS-CoV-2 infection in hospitalized pediatric and adult patients. Sci Transl Med. 2020;12:eabd5487. [CrossRef]

29. Kucirka LM, Lauer SA, Laeyendecker O, Boon D, Lessler J. Variation in False-Negative Rate of Reverse Transcriptase Polymerase Chain Reaction-Based SARS-CoV-2 Tests by Time Since Exposure. Ann Intern Med. 2020;173:262-267. [CrossRef]

30. Nalla AK, Casto AM, Huang M-LW, et al. Comparative Performance of SARS-CoV-2 Detection Assays Using Seven Different Primer-Probe Sets and One Assay Kit. McAdam AJ, ed. J Clin Microbiol. 2020;58:e00557-20. [CrossRef]

31. Moutchia J, Pokharel P, Kerri A, et al. Clinical laboratory parameters associated with severe or critical novel coronavirus disease 2019 (COVID-19): A systematic review and metaanalysis. PLoS One. 2020;15:e0239802. [CrossRef]

32. Tsabouri S, Makis A, Kosmeri C, Siomou E. Risk Factors for Severity in Children with Coronavirus Disease 2019. Pediatr Clin North Am. 2021;68: 321-338. [CrossRef]

33. Wyllie AL, Fournier J, Casanovas-Massana A, et al. Saliva or Nasopharyngeal Swab Specimens for Detection of SARS-CoV-2. N Engl J Med. 2020;383:1283-1286. [CrossRef]

34. Caulley L, Corsten M, Eapen L, et al. Salivary Detection of COVID-19. Ann Intern Med. Published online the 28th of August, 2020:M20-4738. [CrossRef]

35. Weissleder R, Lee H, Ko J, Pittet MJ. COVID-19 diagnostics in context. Sci TransI Med. 2020;12:eabc1931. [CrossRef]

36. de Masson A, Bouaziz J-D, Sulimovic L, et al. Chilblains is a common cutaneous finding during the COVID-19 pandemic: A retrospective nationwide study from France. J Am Acad Dermatol. 2020;83:667-670. [CrossRef]

37. Lu X, Zhang L, Du H, et al. SARS-CoV-2 Infection in Children. N Engl J Med. 2020;382:1663-1665. [CrossRef]

38. Götzinger F, Santiago-García B, Noguera-Julián A, et al. COVID-19 in children and adolescents in Europe: a multinational multicentre cohort study. Lancet Child Adolesc Heal. 2020;4:653661. [CrossRef]

39. Panahi L, Amiri M, Pouy S. Clinical Characteristics of COVID-19 Infection in Newborns and Pediatrics: A Systematic Review. Arch Acad Emerg Med. 2020;8:e50. [CrossRef]

40. Singhal T. A Review of Coronavirus Disease-2019 (COVID-19). Indian J Pediatr. 2020;87:281-286. [CrossRef]

41. Sisk B, Cull W, Harris JM, Rothenburger A, Olson L. National Trends of Cases of COVID-19 in Children Based on US State Health Department Data. Pediatrics. 2020;146:e2020027425. [CrossRef]

42. Sahu KK, Siddiqui AD. From Hematologist's desk: The effect of COVID-19 on the blood system. Am J Hematol. 2020;95:E213-E215. [CrossRef]

43. Qiu $H$, Wu J, Hong L, Luo $Y$, Song $Q$, Chen D. Clinical and epidemiological features of 36 children with coronavirus disease 2019 (COVID-19) in Zhejiang, China: an observational cohort study. Lancet Infect Dis. 2020;20:689-696. [CrossRef]

44. Parri N, Lenge M, Buonsenso D. Children with Covid-19 in Pediatric Emergency Departments in Italy. $\mathrm{N}$ Engl J Med. 2020;383:187-190. [CrossRef]

45. Shen KL, Yang YH, Jiang RM, et al. Updated diagnosis, treatment and prevention of COVID-19 in children: experts' consensus statement (condensed version of the second edition). World $\mathrm{J}$ Pediatr. 2020;16:232-239. [CrossRef]

46. Lal A, Mishra AK, Sahu KK. CT chest findings in coronavirus disease-19 (COVID-19). J Formos Med Assoc. 2020;119:10001001. [CrossRef]

47. Sinha IP, Kaleem M. The role of pulmonary CT scans for children during the COVID-19 pandemic. BMC Med. 2020;18:171. [CrossRef]

48. Gorkem SB, Sirvan Cetin B. COVID-19 pneumonia in a Turkish child presenting with abdominal complaints and reversed halo sign on thorax CT. Diagnostic Interv Radiol. 2020;26:608-609. [CrossRef]

49. Trevisanuto D, Cavallin F, Cavicchiolo ME, Borellini M, Calgaro S, Baraldi E. Coronavirus infection in neonates: a systematic review. Arch Dis Child Fetal Neonatal Ed. Published online the 17th of September, 2020:fetalneonatal-2020-319837. [CrossRef]

50. Chambers C, Krogstad P, Bertrand K, et al. Evaluation for SARS-CoV-2 in Breast Milk From 18 Infected Women. JAMA. 2020;324:1347-1348. [CrossRef]
51. World Health Organization. Feeding and caring for infants and young children of mothers with COVID-19. In: Clinical Management of COVID-19: Interim Guidance. ; 2020:41-44. [CrossRef]

52. Boulad F, Kamboj M, Bouvier N, Mauguen A, Kung AL. COVID-19 in Children With Cancer in New York City. JAMA Oncol. 2020;6:1459-1460. [CrossRef]

53. Shekerdemian LS, Mahmood NR, Wolfe KK, et al. Characteristics and Outcomes of Children With Coronavirus Disease 2019 (COVID-19) Infection Admitted to US and Canadian Pediatric Intensive Care Units. JAMA Pediatr. 2020;174:868. [CrossRef]

54. Tiruneh Tiyare F. Clinical Profile of Covid-19 in Children, Review of Existing Literatures. Pediatr Heal Med Ther. 2020; Volume 11:385392. [CrossRef]

55. Marlais M, Wlodkowski T, Vivarelli $M$, et al. The severity of COVID-19 in children on immunosuppressive medication. Lancet Child Adolesc Heal. 2020;4:e17-e18. [CrossRef]

56. RECOVERY Collaborative Group, Horby P, Lim WS, et al. Dexamethasone in Hospitalized Patients with Covid-19 Preliminary Report. N Engl J Med. Published online the 17th of July, 2020:NEJMoa2021436. [CrossRef]

57. COVID-19 Treatment Guidelines Panel. Coronavirus Disease 2019 (COVID-19) Treatment Guidelines.; 2020. Accessed the 16th of November, 2020. [CrossRef]

58. Chiotos K, Hayes M, Kimberlin DW, et al. Multicenter Initial Guidance on Use of Antivirals for Children With Coronavirus Disease 2019/Severe Acute Respiratory Syndrome Coronavirus 2. J Pediatric Infect Dis Soc. Published online the 22nd of April, 2020:piaa045. [CrossRef]

59. Gilead Sciences. Fact sheet for health care providers emergency use authorization (EUA) of Veklury ${ }^{\circledR}$ (remdesivir). Accessed the 16th of November, 2020. [CrossRef]

60. Rochwerg B, Agoritsas T, Lamontagne $\mathrm{F}$, et al. A living $\mathrm{WHO}$ guideline on drugs for covid-19. BMJ. Published online the 4 th of September, 2020:m3379. [CrossRef]

61. Venturini E, Montagnani C, Garazzino S, et al. Treatment of children with COVID-19: position paper of the Italian Society of Pediatric Infectious Disease. Ital J Pediatr. 2020;46:139. [CrossRef]

62. Agarwal A, Mukherjee A, Kumar G, Chatterjee P, Bhatnagar T, Malhotra P. Convalescent plasma in the management of moderate covid-19 in adults in India: open label phase II multicentre randomised controlled trial (PLACID Trial). BMJ. Published online the 22nd of October, 2020:m3939. [CrossRef]

63. London School of Hygiene \& Tropical Medicine. VaC COVID-19 vaccine tracker. Accessed the 23rd of November, 2020. [CrossRef]

64. Corum J, Wee S-L, Zimmer C. Coronavirus Vaccine Tracker. Accessed the 23rd of November, 2020. [CrossRef]

65. World Health Organization. Draft landscape of COVID-19 candidate vaccines. Accessed the 23rd of November, 2020. [CrossRef]

66. Dufort EM, Koumans EH, Chow EJ, et al. Multisystem Inflammatory Syndrome in Children in New York State. N Engl J Med. 2020;383:347-358. [CrossRef]

67. Whittaker E, Bamford A, Kenny J, et al. Clinical Characteristics of 58 Children With a Pediatric Inflammatory Multisystem Syndrome Temporally Associated With SARS-CoV-2. JAMA. 2020;324:259269. [CrossRef]

68. Sarzaeim M, Rezaei N. Kawasaki Disease and Multisystem Inflammatory Syndrome in Children with COVID-19. SN Compr Clin Med. Published online the 6th of October, 2020:1-6. [CrossRef]

69. Kaushik A, Gupta S, Sood M, Sharma S, Verma S. A systematic review of multisystem inflammatory syndrome in children associated with SARS-CoV-2 infection. Pediatr Infect Dis J. 2020;39:E340-E346. [CrossRef]

70. Abbas K, Procter SR, van Zandvoort K, et al. Routine childhood immunisation during the COVID-19 pandemic in Africa: a benefitrisk analysis of health benefits versus excess risk of SARS-CoV-2 infection. Lancet Glob Heal. 2020;8:e1264-e1272. [CrossRef]

71. Henderson LA, Canna SW, Friedman KG, et al. American College of Rheumatology Clinical Guidance for Multisystem Inflammatory Syndrome in Children Associated With SARS-CoV-2 and Hyperinflammation in Pediatric COVID-19: Version 1. Arthritis Rheumatol. 2020;72:1791-1805. [CrossRef]

72. Cardenas MC, Bustos SS, Enninga EAL, Mofenson L, Chakraborty R. Characterizing and Managing Pediatric SARS-CoV-2 Infection. Learning about the Virus in a Global Classroom. Acta Paediatr. Published online the 11th of November, 2020:apa.15662. [CrossRef] 
73. Impact of the COVID-19 pandemic on global child health: joint statement of the International Child Health Group and the Royal College of Paediatrics and Child Health. Arch Dis Child. Published online the 5th of October, 2020:archdischild-2020-320652. [CrossRef]

74. Nagarajan C. Impact of COVID-19 Pandemic on Violence against Women and Girls, VAWG Helpdesk Research Report No. 311; 2020. [CrossRef]

75. Unicef. COVID-19 and children, Unicef Data Hub. Accessed the 25th of October, 2020. [CrossRef]
76. World Health Organization. WHO urges countries to move quickly to save lives from malaria in sub-Saharan Africa. Accessed the 25th of October, 2020. [CrossRef]

77. WFP Chief warns of hunger pandemic as COVID-19 spreads (Statement to UN Security Council). Accessed the 25th of October, 2020. [CrossRef]

78. Roberton T, Carter ED, Chou VB, et al. Early estimates of the indirect effects of the COVID-19 pandemic on maternal and child mortality in low-income and middle-income countries: a modelling study. Lancet Glob Heal. 2020;8:e901-e908. [CrossRef] 